\title{
Functional mobility and balance in community- dwelling elderly submitted to multisensory versus strength exercises
}

This article was published in the following Dove Press journal:

Clinical Interventions in Aging

5 July 2010

Number of times this article has been viewed

\author{
Fábio Marcon Alfieri' \\ Marcelo Riberto ${ }^{2}$ \\ Lucila Silveira Gatz ${ }^{3}$ \\ Carla Paschoal Corsi \\ Ribeiro ${ }^{2}$ \\ José Augusto Fernandes \\ Lopes $^{2}$ \\ José Maria Santarém ${ }^{4}$ \\ Linamara Rizzo Battistella ${ }^{2}$ \\ 'São Paulo Adventist University \\ Center, São Paulo, Brazil; ${ }^{2}$ Institute of \\ Physical Medicine and Rehabilitation \\ Hospital of Clinics of the University \\ of São Paulo, ${ }^{3}$ Degree in physical \\ education, São Paulo, Brazil; \\ ${ }^{4}$ Coordinator of the Center of \\ Study for Physical Activity Sciences \\ (CECAFI) in the Department of \\ Geriatrics, University of São Paulo
}

Correspondence: Fábio Marcon Alfieri UNASP-Centro Universitário Adventista de São Paulo, Estrada de Itapecerica 5859, São Paulo-SP, Brazil, 05828-00I

Tel +55 II 2 I 286000

Fax +55 II $2 \mid 286465$

Email fabio.alfieri@unasp.edu.br

\begin{abstract}
It is well documented that aging impairs balance and functional mobility. The objective of this study was to compare the efficacy of multisensory versus strength exercises on these parameters. We performed a simple blinded randomized controlled trial with 46 community-dwelling elderly allocated to strength ([GST], $\mathrm{N}=23,70.2$-years-old \pm 4.8 years) or multisensory ([GMS], $\mathrm{N}=23,68.8$-years-old \pm 5.9 years) exercises twice a week for 12 weeks. Subjects were evaluated by blinded raters using the timed 'up and go' test (TUG), the Guralnik test battery, and a force platform. By the end of the treatment, the GMS group showed a significant improvement in TUG $(9.1 \pm 1.9$ seconds (s) to $8.0 \pm 1.0 \mathrm{~s}, P=0.002)$; Guralnik test battery $(10.6 \pm 1.2$ to $11.3 \pm 0.8$ $P=0.009)$; lateromedial $(6.1 \pm 11.7 \mathrm{~cm}$ to $3.1 \pm 1.6 \mathrm{~cm}, P=0.02)$ and anteroposterior displacement $(4.7 \pm 4.2 \mathrm{~cm}$ to $3.4 \pm 1.0 \mathrm{~cm}, P=0.03)$, which were not observed in the GST group. These results reproduce previous findings in the literature and mean that the stimulus to sensibility results in better achievements for the control of balance and dynamic activities. Multisensory exercises were shown to be more efficacious than strength exercises to improve functional mobility.
\end{abstract}

Keywords: older adults, balance, functional mobility, exercises

\section{Introduction}

Aging progressively impairs sight, vestibular input, and somatosensory information, which results in a reduction of environmental perception and precision of movements. ${ }^{1-4}$ On the other hand, aging also impairs functioning of movements by reducing the number of muscle and nerve fibers, which bring a reduction to muscle strength and power. ${ }^{1}$

For these reasons, individuals who are 50 years old may start to experience manifestations of imbalance ${ }^{5}$ and body instability. ${ }^{6}$ Therefore, simple activities like standing up or rising from a chair may become limited or even dangerous, because they are dependent on both gait and balance. ${ }^{2}$

Exercise interventions designed to improve balance are defined as those in which participants exercise their muscles against an external force, as a consequence of voluntary movement or in response to an unexpected perturbation/stimulus, in order to maintain the body's center of mass within manageable limits of the base of support, or in transit to a new base of support. ${ }^{7}$ A variety of exercises involving gait, balance, coordination, functional tasks, strength-training, stretching, 3D exercise (including tai chi, qi gong, dance, yoga), and multisensory exercises, can enhance muscle strength, balance, and mobility in the elderly, reducing the risk of falls. ${ }^{7,8}$

Because the participation in each of these exercise variants are not specifically for the improvement of balance and functional mobility in the elderly, we designed this 
study to check the efficacy of multisensory versus strength exercises in community-dwelling elderly.

\section{Methods \\ Design}

The study was approved by the local ethics committee and all the subjects signed an informed consent form. We chose a randomized, single-blinded controlled trial, with parallel arms. The study was performed in a rehabilitation center for outpatients in the central area of São Paulo, Brazil. Cultural activities and sport for the disabled are also practiced here.

\section{Subjects}

Subjects were recruited from poster advertising in the rehabilitation center and referrals from other health professionals. Most of them were caregivers of patients under rehabilitation in the center, and some were friends who knew about the study by word of mouth.

Inclusion criteria were: aged between 60 and 75 years old; body mass index between 20-30, and the independence to be able to participate in the physical activities. They were excluded if they were under any sort of regular training in the last 3 months; if they presented with any severe clinical or musculoskeletal impairments; had any sort of implanted prosthesis of previous fracture in axial skeleton or lower limbs; visual impairments without correction, or recent complaints of dizziness or falls. They were discontinued from the study if they failed to participate for at least three consecutive training sessions.

\section{Assessments}

Initially, subjects were assessed with the timed 'up and go' (TUG) test, which requires a subject to stand up, walk $3 \mathrm{~m}$ (10 ft), turn, walk back, and sit down. Time taken to complete the test is strongly correlated to level of functional mobility. ${ }^{8,9}$ Afterwards, they were evaluated with the Guralnik test battery. ${ }^{8,10}$ This test battery consists of three items: static balance, ability to stand from a chair, and walking speed. Each item is scored on a scale of 0 to 4 . Static balance is evaluated using three different, progressively more difficult stances starting with the side-by-side stance, moving to the semi-tandem stance, and ending with the tandem stance. To test the ability to rise from a chair, participants are asked to sit with their arms folded across their chests in a straight backed chair placed with its back against a wall, and then to stand up from the chair one time. If they are successful in performing this task, they are asked to stand up and sit down as quickly as possible five times in a row. Timing starts from the signal to start and ends at the final standing position at the end of the fifth stand. For the walking speed test, the participant is instructed to walk a distance of 8 feet $(2.5 \mathrm{~m})$ at their normal pace using any walking aid(s) that they typically require.

An evaluation of the movement of the pressure center during stance was performed with a force platform (AMTI Inc, Watertown, MA). We used the EVA software (Hewlett Packard, Palo Alto, CA) for calibration and the signals were recorded at a frequency of $100 \mathrm{~Hz}$. Amplitude of movement $(\mathrm{cm})$ of the pressure center was assessed in anteroposterior as well as lateromedial planes, and the speed of this movement $(\mathrm{cm} / \mathrm{s})$ were analyzed with Matlab $^{\circledR}$ software (version 6.5). ${ }^{8,11}$

During this assessment, subjects were asked to stand up on the dominant lower limb with eyes open for 10 minutes this was repeated three times. Subjects were asked to focus their sight on an object within $1 \mathrm{~m}$, at eye level. Other environmental conditions like temperature and light were controlled and constant throughout the tests. The rater remained beside the subjects during the tests in order to prevent falls. The assessments were performed before and immediately after the training programs.

\section{Interventions}

Subjects were asked not to participate in other physical activities or change their daily habits during the study. They were randomly allocated in the two training programs using a computer generated list: strength training (GST) or mutlisensory training (GMS). Daily sessions of 1 hour were performed twice weekly for 12 weeks.

\section{Multisensory exercises program}

Multisensory intervention emphasized the stimuli to sensory systems. A warming up period before the activity included short walks and games with balls using the hands or feet. They were followed by stretching exercises for hip muscles, flexors, and extensors of the knee, ankle, and paraspinal muscles. They were performed both standing and lying down.

Resistance exercises for plantar flexors and dorsiflexors as well as squatting and abdominals were performed against gravity in order to strengthen lower limbs and trunk; three series of 10 repetitions were performed for each of these exercises.

Subjects also performed activities to stimulate the plantar surface and dynamic balance. They were asked to walk varied distances forward, backward, and sideways, both with open and closed eyes, and at different speeds. Ground surfaces were varied, including mattresses and different densities of rubber foams. They were also challenged with obstacles like ropes, cones, and sticks. Balance training was performed with devices often directed to this activity in physical therapy; 
according to the subject's ability he might be asked to remain standing on uni- or bipedal support, and with open or closed eyes. These sensorial challenges lasted 20 to 30 minutes.

Finally, training of motor coordination was performed with alternate movements of upper and lower limbs with different positions of head and neck, and with and without visual stimuli.

\section{Strength exercises program}

The muscle strengthening program was performed using six different resistance devices: chest press, rowing, leg press, calves, abdominal, and lumbar extension, with varying resistance. These devices were chosen because they load the main muscle groups.

At each device, the subjects were oriented to perform three series of exercises with varying load: the first (12 repetitions) with a load correspondent to $50 \%$ of the maximum; the second (10 repetitions) with $75 \%$ of the maximum, and the last (eight repetitions) with the maximum tolerated load. In the first day of training the subjects did the exercises with no load, to get used to the movements and posture. This value was estimated by successive trials and was defined as the load compatible with a complete range of motion, without a slow concentric or eccentric contraction or sustained apnea. This value would then be recorded to set new limits for the next session. The load was increased whenever it was possible to complete the last series of eight repetitions. Complaints of pain and breathing discomfort were actively sought, as well as a constant monitoring of speed of movements both in the concentric and eccentric phases.

\section{Statistical analysis}

Data analysis was performed with the statistical package SigmaStat 3.5 for Windows. We used the principle of 'intention to treat' to deal with possible dropouts, and missing data were inputted with the mean of the remaining data. The results were described using means and standard deviations. Comparisons of means at baseline between groups were performed using a two-tailed, independent student's t test or Mann-Whitney U-test. Comparisons within the groups after the treatment were done with paired Student $t$ test or Wilcoxon signed-rank test, according to data distribution. The effect of intervention was determined by two-way analysis of variance (ANOVA) with repeated measures (groups $\times$ time). Significance level was 0.05 .

\section{Results}

Sixty-nine individuals were recruited, 6 refused to participate, 17 were excluded ( 8 were doing regular physical activities, 2 had joint prosthesis implanted in the lower limbs,
2 had disabling lower back pain, 1 was in a multidisciplinary therapeutic program for fibromyalgia, and 4 had uncontrolled blood pressure). The remaining 46 subjects were allocated by simple randomization: 23 for strength training (GST) and 23 for multisensory training (GMS). By the end of the study, the GST group had 5 drop-outs (1 ankle fracture, one rib fracture, 1 uncontrolled heart failure, 1 knee pain and $1 \mathrm{e}$ giving up) while there were also 5e drop-outs in the GMS group ( 5 giving up). General characteristics of both groups are presented in Table 1.

Before the intervention functional mobility was evaluated by the TUG test and the Guralnik test battery, as well as using parameters of balance like the displacement of the center of pressure in force plates. For both groups, results were similar (Table 2).

However, after 3 months of training, subjects in GMS showed a statistically significant reduction in both scores, which was not present with GST. The GST group showed reduction in the speed of displacement of the center of pressure after 3 months of training, while the GMS group reduced both the anteroposterior and lateromedial displacement of the center of pressure (Table 2). The comparison of the amount of improvement in functional mobility of each group showed that only in TUG was this difference statistically significant, on the other hand, the amount of reduction of the balance parameters did not show statistical significance between the groups (Table 2).

\section{Discussion}

These results show that the regular practice of physical exercises can positively impact on balance and functional mobility in community-dwelling elderly.

Multisensory exercises are performed on a variety of surfaces, with different textures and densities, as well as with balls, activities, and a series of equipment which stimulate balance. ${ }^{12}$ The fact that this sort of training brings stimuli to visual, vestibular and somatosensory systems is likely the reason for the improvement in GMS after the intervention. Examples of this are the massage of plantar soles with tennis

Table I General characteristics of GST and GMS groups

\begin{tabular}{llll}
\hline & GST & GMS & $P$ \\
\hline $\mathrm{N}$ & 23 & 23 & \\
$\mathrm{~F} / \mathrm{M}$ & $22 / \mathrm{I}$ & $22 / \mathrm{I}$ & \\
Age $($ years $)$ & $70.2 \pm 4.8$ & $68.8 \pm 5.9$ & 0.47 \\
BMI $\left(\mathrm{kg} / \mathrm{cm}^{2}\right)$ & $28.1 \pm 3.3$ & $26.9 \pm 3.5$ & 0.30 \\
\hline
\end{tabular}

Notes: Values are presented as mean (SD).

Abbreviations: N, number; BMI, body mass index; F, female; M, male; GST, group of strength training; GMS, group of multisensory training. 
Table 2 Modification of parameters of functional mobility and balance from baseline to the end of training in GST and GMS groups

\begin{tabular}{|c|c|c|c|c|c|c|c|}
\hline & \multicolumn{3}{|l|}{ GST } & \multicolumn{3}{|l|}{ GMS } & \multirow[t]{2}{*}{$\boldsymbol{P}^{*}$} \\
\hline & Before & After & $P$ & Before & After & $P$ & \\
\hline TUG (s) & $8.8 \pm 2.3$ & $8.5 \pm 2.1$ & 0.17 & $9.1 \pm 1.9$ & $8.0 \pm 1.0$ & 0.002 & 0.03 \\
\hline Guralnik & $10.5 \pm 0.9$ & $10.8 \pm 0.6$ & 0.12 & $10.6 \pm 1.2$ & $11.3 \pm 0.8$ & 0.009 & 0.40 \\
\hline A/P displ (cm) & $4.9 \pm 4.8$ & $3.8 \pm 1.5$ & 0.36 & $4.7 \pm 4.2$ & $3.4 \pm 1.0$ & 0.03 & 0.50 \\
\hline L/M displ (cm) & $7.6 \pm 18.7$ & $3.4 \pm 2.8$ & 0.61 & $6.1 \pm 11.7$ & $3.1 \pm 1.6$ & 0.02 & 0.30 \\
\hline $\mathrm{SD}(\mathrm{cm} / \mathrm{s})$ & $6.9 \pm 4.2$ & $5.7 \pm 1.5$ & 0.03 & $5.5 \pm 1.7$ & $5.4 \pm 1.1$ & 0.40 & 0.08 \\
\hline
\end{tabular}

$P^{*}$, test for group $\times$ time.

Abbreviations: TUG, timed up and go; displ, displacement of center of pressure; A/P, anteroposterior, L/M, lateromedial; s, seconds; cm, centimeters; cm/s, centimeters per second; SD, speed of displacement; GST, group of strength training; GMS, group of multisensory training.

balls and walking on different surfaces, which are shown to generate an important proprioceptive input for maintenance of attitudes of body parts between each other. ${ }^{13}$ Although strength exercises have also been shown to bring such benefits and stimulate the musculoskeletal system in terms of muscle mass and strength, ${ }^{14-16}$ they were not associated with improvement of postural control in this group of volunteers.

Studies similar to this have reported that multisensory exercises are appropriate for improvement of balance in the elderly; however they only refer to series of patients, or compare them to people without any intervention. ${ }^{17-22}$

The only study that compared a group of multisensory exercises with a group of strength exercises, carried out the exercises for both groups using machines. ${ }^{23}$ These are not enough to promote a better postural control. It should be noted that the participants performed only strength exercises for the lower body. Another study also reported that muscle strength exercises failed to promote balance improvement in another series of patients. ${ }^{24}$

Static balance is very important because it predicts the risk of falls. ${ }^{8,25}$ It is directly associated with daily activities like the use of public transportation or moving the body center of mass to reach an object.

Subjects under GST significantly reduced the speed of pressure center movement while standing. However, the amount of displacement was not significantly changed. On the other hand, subjects under GMS reduced the distance of the movement of pressure center, but not the speed of this movement. This suggests that with a massive sensorial stimulation, subjects in this second group have developed strategies of postural control, resulting in a reduction in body sway. ${ }^{22}$ The decrease in body oscillationin the lateromedial direction for this group is important because many activities that put older adults at risk for falls involve movements in the lateral direction. ${ }^{22,25}$

Measuring functional mobility is an adequate way to assess dynamic balance in daily situations. Although muscle strength is related to the performance in gait in the elderly, programs with strength exercises like those in the GST group did not show any effect on this parameter in the elderly. ${ }^{14,16}$ While strength exercises for 14 weeks have proved to increase gait speed in up to $3.4 \%$ in the elderly, ${ }^{26}$ the association of balance exercises to them can result in increases of as much as $8 \%$ in gait speed. ${ }^{27}$ In this study, strength exercises resulted in amelioration of $3 \%$ in the TUG test, while multisensory stimulation heightened this parameter in $11.85 \%$, and the difference between the groups reached statistical significance. A statistically significant improvement of $13.6 \%$ in TUG scores after only 8 weeks of multisensory training was also observed in another study. ${ }^{22}$

Our results showed that strength exercises showed little influence in functional activities, as assessed by the TUG and Guralnik tests. This can be explained by the fact that all exercises were performed in the sitting position, depriving these individuals of proprioceptive information on the upright position, ${ }^{14}$ which is the position where ability to balance is most evident. ${ }^{24}$

The difference in improvement in functional mobility between the groups may be relative to the fact that strength exercises do not involve changes of position or agility, which are tasks very frequently performed in multisensory exercises. ${ }^{12}$ Exercises performed with balls on unstable surfaces, with different head positions, and exercises combined with visual suppression, should be used to improve postural control on the senior population because they involve visual, vestibular, somatosensory and musculoskeletal systems, increasing receptors' sensitivity, and providing better conditions for balance control. ${ }^{8,12}$

It must be stressed that all of the subjects in this study were in the seventh decade of life, when physiologic functions related to balance are often less effective and falls represent a threat. ${ }^{25}$ Improving both static and dynamic balance means a better and safer performance of daily activities, functional independence, and reduction of falls. ${ }^{8,28}$

One of the limitations of this study is the lack of a control over people who did not perform any training. This would support the conclusion that these results are due to the effect of training and not due to chance. Besides that, such a 
reduced sample may have prevented us from demonstrating differences between the interventions, but we believe this may not be a problem, since our results repeat some findings in the literature. ${ }^{7}$ The position in which the activities were done is an issue that must be taken into account. Strength exercises for the elderly performed in different positions may bring results different than ours.

This study showed that multisensory exercises are more efficacious than strength exercises performed in isolation, for the improvement of functional mobility in the elderly. Both sorts of trainings caused changes in postural control, although the multisensory ones seemed to have more consistent findings.

\section{Acknowledgments}

The authors thank Leslie Andrews Portes for assistance with data analysis and for statistical assistance; Carolina Rodini, Luana Talita Diniz Ferreira, and Gemal Emanuel Pirré for assistance in subject recruitment and performing the training. We acknowledge the contribution of Marcelo Alves Mourão and Adilson Gonçalves for assessment of subjects' functioning.

\section{Disclosure}

The authors report no conflicts of interest.

\section{References}

1. Alexander NB. Postural control in older adults. JAm Geriatric Soc. 1994; 42: $93-108$.

2. Shumway-Cook A, Woollacott M. Motor Control: Theory and Practical Applications. Baltimore: Williams \& Wilkins; 1995.

3. Woollacott M, Shumway-Cook A. Attention and the control of posture and gait: a review of an emerging area of research. Gait Posture. 2002; $16: 1-14$.

4. Shaffer SW, Harrison, AL. Aging of the somatosensory system: a translational perspective. Phys Ther. 2007;87:193-207.

5. Teasdale N, Simoneau M. Attentional demands for postural control: the effects of aging and sensory reintegration. Gait Posture. 2001;14:203-210.

6. Amiridis IG, Hatzitaki V, Arabatzi F. Age-induced modifications of static postural control in humans. Neurosci Lett. 2003;350:1-4.

7. Howe TE, Rochester L, Jackson A, Banks PMH, Blair VA. Exercise for improving balance in older people. Cochrane Database Syst Rev. 2007;3. Art. No. CD004963. DOI:10.1002/14651858.CD004963. Pub 2.

8. Rogers ME, Rogers NL, Takeshima N, Islam MM. Methods to assess and improve the physical parameters associated with fall risk in older adults. Prev Med. 2003;36:255-264.

Clinical Interventions in Aging

\section{Publish your work in this journal}

Clinical Interventions in Aging is an international, peer-reviewed journal focusing on evidence-based reports on the value or lack thereof of treatments intended to prevent or delay the onset of maladaptive correlates of aging in human beings. This journal is indexed on PubMed Central, MedLine, the American Chemical Society's 'Chemical
9. Podsiadlo D, Richardson S. The timed 'up and go': a test of basic functional mobility for frail elderly persons. J Am Geriatr Soc. 1991; 39:142-148.

10. Guralnik JM, Simonsick EM, Ferrucci L, et al. A short physical performance battery assessing lower extremity function: association with self-reported disability and prediction of mortality and nursing home admission. J Gerontol Med Sci. 1994;49:M85-M94.

11. Raymakers JA, Samson MM, Verhaar HJJ. The assessment of body sway and the choice the stability parameter(s). Gait Posture. 2005; 21:48-58.

12. Alfieri FM, Guirro RRJ, Teodori RM. Postural stability of elderly submitted to multisensorial physical therapy intervention. Electromyogr Clin Neurophysiol. 2009;49:9 [In press].

13. Perrin PP, Gauchard GC, Perrot C, Jeandel C. Effects of physical and sporting activities on balance control in elderly people. $\mathrm{Br} J$ Sports Med. 1999;33:121-126.

14. Barry BK, Carson RG. The consequences of resistance training for movement control in older adults. J Gerontol. 2004;59(7):730-754.

15. Latham NK, Bennett DA, Stretton CM, Anderson CS. Systematic review of progressive resistance strenght training in older adults. $J$ Gerontol. 2004;59(1):48-61.

16. Orr R, Raymond J, Sigh MF. Efficacy of progressive resistance training on balance performance in older adults. Sports Med. 2008; 38(4):317-343.

17. Gauchard GC, Jeandel C, Perrin PP. Physical and sporting activities improve vestibular afferent usage and balance in elderly human subjects. Gerontology. 2001;47:263-270.

18. Hu MH, Woollacott MH. Multisensory training of standing balance in older adults: postural stability and one-leg stance balance. $J$ Gerontol. 1994;49:M52-M61.

19. Judge JO, Lindsey C, Underwood M, Winsemius D. Balance improvements in older women: effect of exercise training. Phys Ther. 1993; 73:254-262.

20. Kronhed AC, Moller C, Olsson B, Moller M. The effect of short-term balance training on community dwelling older adults. J Aging Phys Act. 2001;9:19-31.

21. Rogers ME, Fernandez JE, Bohlken RM. Training to reduce postural sway and increase functional reach in the elderly. $J$ Occup Rehabil. 2001;11(4):291-298.

22. Nagy E, Feher-Kiss A, Márnai B, Domján-Preszner A, Angyan L, Horvath G. Postural control in elderly subjects participating in balance training. Eur J Appl Physiol. 2007;100:97-104.

23. Bruin ED, Murer K. Effect of additional functional exercises on balance in elderly people. Clin Rehabil. 2007;21:112-121.

24. Bellew JW, Yates JW, Gater DR. The initial effects of low-volume strength training on balance in untrained older men and women. J Strength Cond Res. 2003;17:121-128.

25. Islam MM, Nasu E, Rogers ME, Koizumi D, Rogers Nl, Takeshima N. Effects of combined sensory and muscular training on balance in Japanese older adults. Prev Med. 2004;39(6):1148-1155.

26. Topp RT, Mikesky A, Dayhoff NE, Holt W. Effect of resistance training on strength, postural control, and gait velocity among older control, and gait velocity among older adults. Clin Nurs Res. 1996;5(4):407-427.

27. Judge JO, Underwood M, Gennosa T. Exercise to improve gait velocity in older persons. Arch Phys Med Rehabil. 1993;74:400-406.

28. Marigold DS, Patla AE. Age-related changes in gait for multi-surface terrain. Gait Posture. 2008;27:689-696.

\section{Dovepress}

Abstracts Service' (CAS), Scopus and the Elsevier Bibliographic databases. The manuscript management system is completely online and includes a very quick and fair peer-review system, which is all easy to use. Visit http://www.dovepress.com/testimonials.php to read real quotes from published authors. 